\title{
PREDICTIVE VALUE OF ULTRASONOLOGICAL CHARACTERISTICS OF A THYROID NODULE IN THE DIAGNOSIS OF MALIGNANCY
}

\author{
Sajikumar N. Raghavan', Ramkumar Venugopala Panicker ${ }^{2}$ \\ ${ }^{1}$ Additional Professor, Department of General Surgery, Government T. D. Medical College, Alappuzha. \\ ${ }^{2}$ Senior Resident, Department of General Surgery, Government T. D. Medical College, Alappuzha.
}

\section{ABSTRACT}

\section{BACKGROUND}

B-mode high resolution ultrasonography is a preferred diagnostic modality for the detection of intrathyroidal lesions. The study aimed to assess the diagnostic capability of HRUSG in detecting malignancy in discrete thyroid nodules.

\section{MATERIALS AND METHODS}

50 patients with clinically detected solitary nodule of thyroid underwent ultrasound examination with high frequency (5 - $12 \mathrm{MHz}$ ) linear array transducer initially. The patients proceeded to definitive surgery and the histopathological report was compared with ultrasound characters. A structured, pre-prepared case proforma was used to collect the data.

\section{RESULTS}

The ultrasound character most predictive of malignancy were hypoechogenicity, microcalcifications and being taller than wide with a sensitivity of $83 \%, 75 \%$ and $75 \%$ respectively. Maximum negative predictive values are observed for the criteria of a nodule being taller than wide (91.4\%) and lacking microcalcification $(90.6 \%)$.

\section{CONCLUSION}

In this study, we performed the prospective analysis of the sonological findings in correlation with tissue diagnosis. The most predictive of malignant tissue diagnosis were presence of hypoechogenicity, microcalcifications and nodules being taller than wide. The evaluation of the cases was prospective, but the sample size was relatively small. However, the results of our study were encouraging in that we were able to identify the most appreciable ultrasonological features for differentiating benign from malignant solid nodules.

\section{KEYWORDS}

Thyroid Gland, Ultrasonography, Papillary Carcinoma.

HOW TO CITE THIS ARTICLE: Raghavan SN, Panicker RV. Predictive value of ultrasonological characteristics of a thyroid nodule in the diagnosis of malignancy. J. Evolution Med. Dent. Sci. 2017;6(24):1963-1967, DOI: 10.14260/Jemds/2017/430

\section{BACKGROUND \\ Thyroid diseases are arguably among the commonest endocrine disorders worldwide. Thyroid disorders can vary from innocent physiologic enlargements of the gland to life- threatening thyrotoxic crises, which require emergency medical interventions and thyroid cancers, which require skilful surgical management. The appropriate management and successful outcome depends on accurate diagnosis of the thyroid disease. Carcinoma of the thyroid gland is the most common endocrine malignancy in the world, and worldwide it constitutes about $1 \%$ of human neoplasms. ${ }^{1}$ Thyroid carcinoma accounts for $1 \%$ - $5 \%$ of all malignancies in females and less than $2 \%$ of all malignancies in males. ${ }^{2}$ Papillary carcinoma is the most common thyroid neoplasm accounting for $70 \%-80 \%$ of thyroid carcinoma. ${ }^{3}$ The incidence of thyroid carcinoma and particularly papillary carcinoma has been on the rise around the globe. ${ }^{2}$ Most}

Financial or Other, Competing Interest: None.

Submission 02-03-2017, Peer Review 15-03-2017,

Acceptance 17-03-2017, Published 22-03-2017.

Corresponding Author:

Dr. Sajikumar N. Raghavan,

Additional Professor,

Department of General Surgery,

T. D. Medical College,

Alappuzha-688005, Kerala.

E-mail: drsajikumarnr@gmail.com

DOI: $10.14260 /$ jemds $/ 2017 / 430$ patients with thyroid carcinoma, especially papillary carcinoma can expect an excellent prognosis with a 10-year survival rates above $95 \%$ for the most favourable stages. ${ }^{3}$ Hence, early detection of thyroid carcinoma is very important.

Clinically, discrete swellings in the thyroid gland known as solitary nodules of the thyroid have a higher incidence of malignancy than a non-solitary nodule. ${ }^{4}$ The incidence of malignancy in solitary thyroid nodule ranges from $5 \%$ to $15 \% .3,5,6$ A thyroid nodule is defined as any discrete lesion that is sonographically distinguishable from the adjacent thyroid parenchyma. ${ }^{7}$ The evaluation of patients with clinically discrete swelling aims at identifying the presence or absence of a disorder of function or malignancy and aid in recognising those patients who require surgical intervention and to avoid inappropriate surgery in those with benign asymptomatic swellings. The practising clinician relies upon clinical information and judicious use of available diagnostic aids. Among the modern imaging modalities, high-resolution ultrasound is the first choice and most sensitive diagnostic modality for the detection of intrathyroidal lesions and it is necessary to perform ultrasonography for nodules found after palpation. ${ }^{8}$ Because of its superficial location, the thyroid gland is ideally suited for high-frequency sonography (using $5-12 \mathrm{MHz}$ linear array transducer), which facilitates the detection of even clinically non-palpable nodules of $2-3$ $\mathrm{mm}$ size and allows a more accurate morphological characterisation of the lesion. ${ }^{9}$ The prevalence of thyroid 
nodules detected by palpation is $3 \%-7 \%$ in most series and it increases with age in areas of iodine deficiency and with exposure to external radiation. But using high resolution ultrasound it has been shown that more than $50 \%$ of adults have thyroid nodules.10 Sonological characters including nodule size, internal content, nodule shape, nodule margin, echogenicity, calcification, extracapsular invasion, vascularity and elastography are assessed to identify suspicious nodules. ${ }^{11}$

Documentation of nodule size during the initial scan is important to assess the interval growth of the nodule during followup. Rapid increase in size of the nodule is a predictor of malignancy. ${ }^{12}$ Solid or predominantly solid nodules have a higher risk of malignancy than do mixed or predominantly cystic nodules. Cystic and almost completely cystic nodules have a very low likelihood of being malignant. Nodules with mixed composition have an average risk of malignancy. ${ }^{7}$ The dimensions of the nodule are checked in the anteroposterior and transverse dimensions. A thyroid nodule which has a greater anteroposterior than transverse diameter (i.e. taller than wider) has been described as more likely to be malignant than benign. ${ }^{13}$ The advent of high frequency ultrasound has allowed us to better characterise the margins of a thyroid nodule. Microlobulated or spiculated margins are suggestive of malignancy. ${ }^{13}$ Thyroid nodules may be classified as hypoechoic, isoechoic or hyperechoic in comparison to adjacent thyroid parenchyma and strap muscles. ${ }^{11} \mathrm{~A}$ hypoechoic nodule has increased risk of malignancy, but it is more so for a nodule with marked hypoechogenicity. Presence of microcalcifications and macrocalcifications are associated with malignancy. Pathologically, microcalcification is a psammoma body that is comprised of $10-100 \mu \mathrm{m}$ sized round, laminar, crystalline, calcific deposits which is very specific for thyroid carcinoma and especially for papillary thyroid carcinoma. Moon et al in their study on thyroid sonography reports a specificity of $86 \%-95 \%$ and a positive predictive value of $42 \%-94 \%$ for the presence of microcalcifications and associated malignancy. ${ }^{11}$ Yoon et al did not find any significant association between the presence of rim calcifications and malignancy in a thyroid nodule. ${ }^{14}$ Tumour vascularity, extracapsular invasion and elastography are other important characters that needs to be assessed. Frates et al in a review of various studies focusing on the sonological features of thyroid nodules and their association with malignancy found out that hypoechogenic nature of a nodule has maximum sensitivity $(26.4 \%$ - $87.1 \%)$ and presence of microcalcifications has maximum specificity $(85.8 \%-95 \%)$ in the identification of thyroid malignancy. ${ }^{7}$ The identification of suspicious nodules by ultrasound helps in obtaining targeted FNACs (Fine needle aspiration cytology). Cai X J et al, in a study to assess the inadequate aspirate from FNAC found that the inadequacy rate was significantly lower for USG-guided FNAC (6.4\%) than conventional FNAC (13\%). ${ }^{15}$ Solymosi et al, in a study comparing FNAC with and without USG guidance found that the positive predictive value of FNAC (45\% v/s 16\%), specificity (87\% v/s 56\%), sensitivity (92\% v/s 57\%) and diagnostic accuracy (87\% v/s 66\%) were all higher with USGguided FNAC. 16
Thus, it is clear that ultrasound increases the detection of thyroid nodules and helps in identification of suspicious nodules, thus improving the diagnostic capability of guided FNAC.

\section{MATERIALS AND METHODS}

The study was conducted in patients with solitary thyroid nodules attending the outpatient and inpatient department of general surgery on T.D.M.C.H. Vandanam over a period of one year from January 2013 to January 2014.

Study Design- Descriptive study.

\section{Inclusion Criteria}

Patients with solitary nodule of thyroid on clinical examination who underwent pre-operative ultrasound evaluation and proceeded to thyroidectomy.

\section{Study Procedure}

High frequency ultrasonography was done using ultrasound system with high frequency $(5-12 \mathrm{MHz}$ ) probe in a group of 50 patients who presented with clinically diagnosed solitary nodule of thyroid. Various features of the nodule like shape, margin, echogenicity and calcification were assessed. Patients who proceeded to thyroidectomy were included in the study. The association between above mentioned sonological characters and malignancy were statistically analysed in 12 patients who had histopathologically proven malignancy. Informed consent was taken prior to the procedure.

\section{Statistical Analysis}

Qualitative variables were summarised using percentages and proportions. Quantitative variables were summarised using mean with standard deviation. Sensitivity and specificity, each of the above mentioned sonological characters were found out by comparing it with histopathologic examination report. Data was entered in MS Excel data sheet and analysed using SPSS software.

\section{RESULTS}

Among the 50 patients, there were 10 cases of papillary carcinoma and 2 cases of follicular carcinoma (Table I and Figure I). Ultrasonological characteristics of the nodule-like hypoechogenicity, taller than wide dimensions, presence of spiculated margins, macrocalcifications and microcalcifications were assessed. Statistical analysis was done to find out correlation between these characters and malignancy in 12 histopathologically proven cases of malignancy. The presence of hypoechogenicity, microcalcifications and being taller than wide were highly suggestive of a malignant thyroid nodule with a sensitivity of $83 \%, 75 \%$ and $75 \%$ respectively (Tables II, III, IV, V, X, XI and Figures II, III, IV). Maximum negative predictive values are observed for the criteria of a nodule being taller than wide (91.4\%) and lacking microcalcification $(90.6 \%)$ as shown in Tables IV, V, X, XI and Figures III and VI. Hence, a nodule not being taller than wide and lacking microcalcification has more than $90 \%$ chance of not being malignant. Spiculated margins are highly specific for malignant nodules, and there is $90 \%$ accuracy in detection of a malignant nodule using this criterion (Tables VI, VII and Figure IV). 


\begin{tabular}{|c|c|c|}
\hline Histopathology Report & Count & Percentage \\
\hline Papillary Carcinoma & 10 & 20 \\
\hline Follicular Carcinoma & 2 & 4 \\
\hline Colloid Nodule & 38 & 76 \\
\hline
\end{tabular}

Table I. Histopathology Reporting of the Study Population Correlation of Hypoechogenicity of Thyroid Nodule with Malignancy

\begin{tabular}{|c|c|c|c|}
\hline \multirow[b]{2}{*}{ Hypoechoic } & \multicolumn{3}{|c|}{ Class } \\
\hline & Malignant & Benign & Total \\
\hline Yes & 10 & 28 & 38 \\
\hline No & 2 & 10 & 12 \\
\hline Total & 12 & 38 & 50 \\
\hline \multicolumn{4}{|c|}{$\begin{array}{c}\text { Table II. Correlation of Hypoechogenicity } \\
\text { of Thyroid Nodule with Malignancy }\end{array}$} \\
\hline
\end{tabular}

\begin{tabular}{|c|c|}
\hline Sensitivity & $83.30 \%$ \\
\hline Specificity & $26.30 \%$ \\
\hline False Negative & $16.70 \%$ \\
\hline False Positive & $73.70 \%$ \\
\hline Predictive Value of Positive Test & $26.30 \%$ \\
\hline Predictive Value of Negative Test & $83.30 \%$ \\
\hline Accuracy & $40.00 \%$ \\
\hline \multicolumn{2}{|c|}{$\begin{array}{l}\text { Table III. Prediction of Hypoechogenicity of } \\
\text { Thyroid Nodule being associated with Malignancy }\end{array}$} \\
\hline
\end{tabular}

Correlation of Taller than Wide Dimension of Thyroid Nodule with Malignancy

\begin{tabular}{|c|c|c|c|}
\hline \multirow{2}{*}{ Taller than Wide } & \multicolumn{3}{|c|}{ Class } \\
\cline { 2 - 4 } & Malignant & Benign & Total \\
\hline Yes & 9 & 6 & 15 \\
\hline No & 3 & 32 & 35 \\
\hline Total & $\mathbf{1 2}$ & $\mathbf{3 8}$ & $\mathbf{5 0}$ \\
\hline \multicolumn{3}{|c|}{ Table IV. Correlation of Taller than wide } \\
Dimension of Nodule with Malignancy \\
\hline
\end{tabular}

\begin{tabular}{|c|c|}
\hline Sensitivity & $75.00 \%$ \\
\hline Specificity & $84.20 \%$ \\
\hline False Negative & $25.00 \%$ \\
\hline False Positive & $15.80 \%$ \\
\hline Predictive Value of Positive Test & $60.00 \%$ \\
\hline Predictive Value of Negative Test & $91.40 \%$ \\
\hline Accuracy & $82.00 \%$ \\
\hline
\end{tabular}

Correlation of Spiculated Margins in the Thyroid Nodule with Malignancy

\begin{tabular}{|c|c|c|c|}
\hline \multirow{2}{*}{ Spiculated Margins } & \multicolumn{3}{|c|}{ Class } \\
\hline & Malignant & Benign & Total \\
\hline Yes & 7 & 0 & 7 \\
\hline No & 5 & 38 & 43 \\
\hline Total & 12 & 38 & 50 \\
\hline \multicolumn{4}{|c|}{$\begin{array}{c}\text { Table VI. Correlation of Spiculated Margins } \\
\text { of the Thyroid Nodule with Malignancy }\end{array}$} \\
\hline
\end{tabular}

\begin{tabular}{|c|c|}
\hline Sensitivity & $58.30 \%$ \\
\hline Specificity & $100.00 \%$ \\
\hline False Negative & $41.70 \%$ \\
\hline False Positive & $0.00 \%$ \\
\hline
\end{tabular}

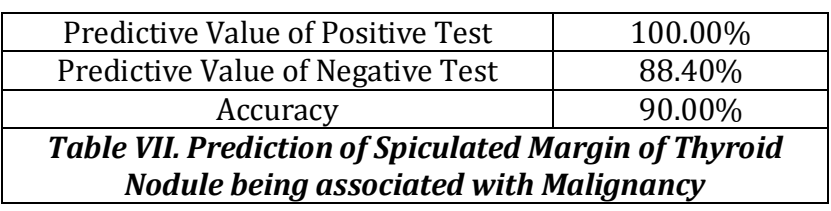

Correlation of Macrocalcifications in the Thyroid Nodule with Malignancy

\begin{tabular}{|c|c|c|c|}
\hline \multirow{2}{*}{ Macrocalcifications } & \multicolumn{3}{|c|}{ Class } \\
\hline & Malignant & Benign & Total \\
\hline Yes & 3 & 7 & 10 \\
\hline No & 9 & 31 & 40 \\
\hline Total & 12 & 38 & 50 \\
\hline $\begin{array}{l}\text { Table VIII. Corl } \\
\text { in the Thyro }\end{array}$ & $\begin{array}{l}\text { tion of Mac } \\
\text { Nodule with }\end{array}$ & $\begin{array}{l}\text { alcificati } \\
\text { alignancy }\end{array}$ & \\
\hline
\end{tabular}

\begin{tabular}{|c|c|}
\hline Sensitivity & $25.00 \%$ \\
\hline Specificity & $81.60 \%$ \\
\hline False Negative & $75.00 \%$ \\
\hline False Positive & $18.40 \%$ \\
\hline Predictive Value of Positive Test & $30.00 \%$ \\
\hline Predictive Value of Negative Test & $77.50 \%$ \\
\hline Accuracy & $68.00 \%$ \\
\hline \multicolumn{2}{|c|}{$\begin{array}{l}\text { Table IX. Prediction of Macrocalcification in } \\
\text { Thyroid Nodule being associated with Malignancy }\end{array}$} \\
\hline
\end{tabular}

Correlation of Microcalcifications in Thyroid Nodule with Malignancy

\begin{tabular}{|c|c|c|c|}
\hline \multirow{2}{*}{ Microcalcifications } & \multicolumn{3}{|c|}{ Class } \\
\hline & Malignant & Benign & Total \\
\hline Yes & 9 & 9 & 18 \\
\hline No & 3 & 29 & 32 \\
\hline Total & 12 & 38 & 50 \\
\hline $\begin{array}{r}\text { Table X. Corre } \\
\text { in Thyroid }\end{array}$ & $\begin{array}{l}\text { ion of Micro } \\
\text { dule with } M\end{array}$ & $\begin{array}{l}\text { cificatio } \\
\text { gnancy }\end{array}$ & \\
\hline
\end{tabular}

\begin{tabular}{|c|c|}
\hline Sensitivity & $75.00 \%$ \\
\hline Specificity & $76.30 \%$ \\
\hline False Negative & $25.00 \%$ \\
\hline False Positive & $23.70 \%$ \\
\hline Predictive Value of Positive Test & $50.00 \%$ \\
\hline Predictive Value of Negative Test & $90.60 \%$ \\
\hline Accuracy & $76.00 \%$ \\
\hline \multicolumn{2}{|c|}{$\begin{array}{c}\text { Table XI. Prediction of Microcalcification in Thyroid } \\
\text { Nodule being associated with Malignancy }\end{array}$} \\
\hline
\end{tabular}

\begin{tabular}{|c|c|c|c|c|c|}
\hline & $\begin{array}{c}\text { Hypo- } \\
\text { echoic }\end{array}$ & $\begin{array}{c}\text { Taller } \\
\text { Than } \\
\text { Wide }\end{array}$ & $\begin{array}{c}\text { Spiculated } \\
\text { Margins }\end{array}$ & $\begin{array}{c}\text { Macro- } \\
\text { Calcification }\end{array}$ & $\begin{array}{c}\text { Micro- } \\
\text { Calcification }\end{array}$ \\
\hline Sensitivity & 83.3 & 75 & 58.3 & 25 & 75 \\
\hline Specificity & 26.3 & 84.2 & 100 & 81 & 76.3 \\
\hline PPV & 26.3 & 60 & 100 & 30 & 50 \\
\hline NPV & 83.3 & 91.4 & 88.4 & 77.5 & 90.6 \\
\hline Accuracy & 40 & 82 & 90 & 68 & 76 \\
\hline \multicolumn{6}{|c|}{ Table XII. Comparison of the Diagnostic Indices of } \\
Ultrasonological Parameters in Detecting Malignancy* \\
\hline
\end{tabular}

*All values in percentage. 


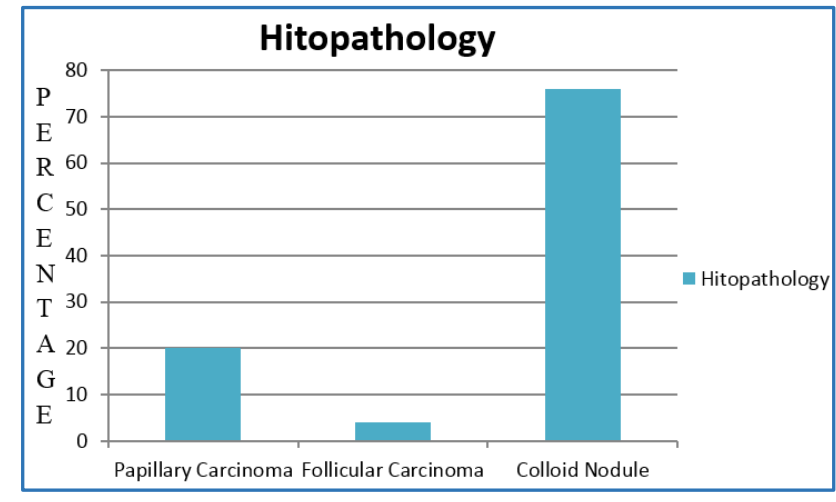

Figure I. Histopathology Reporting of the Study Population

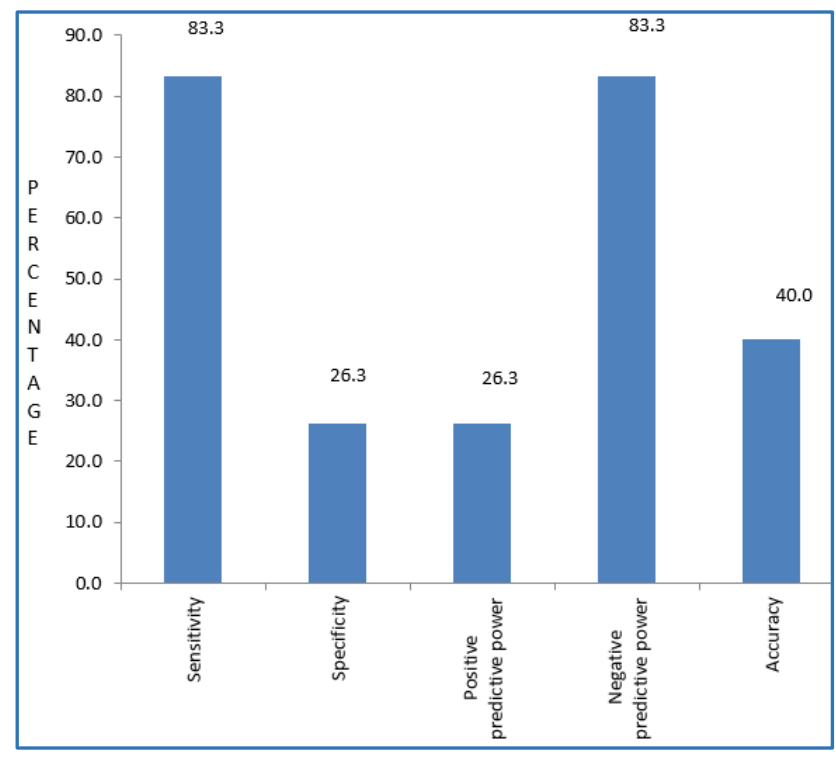

Figure II. Prediction of Hypoechogenicity of Thyroid Nodule being associated with Malignancy

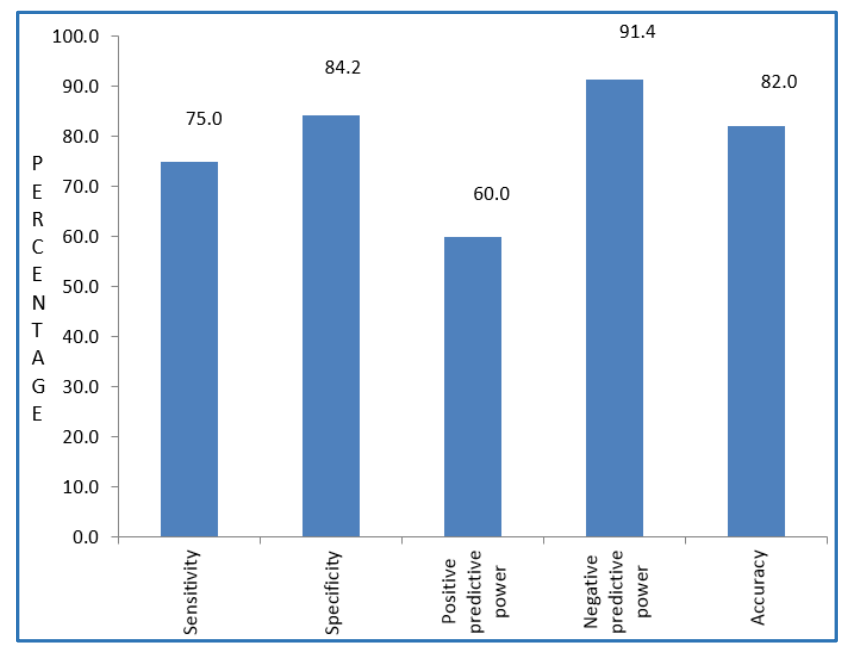

Figure III. Prediction of Taller than Wide Dimension of Thyroid Nodule being associated with Malignancy

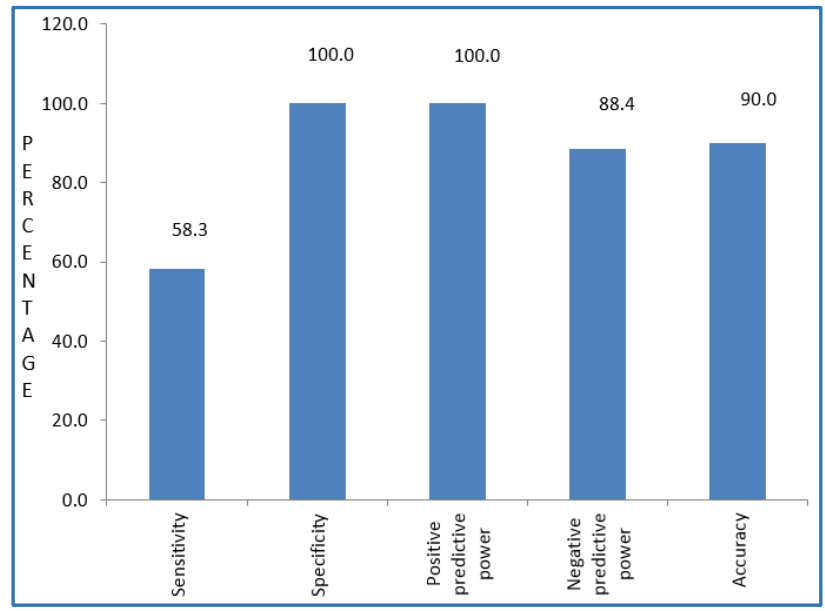

Figure IV. Prediction of Spiculated Margin of Nodule being associated with Malignancy

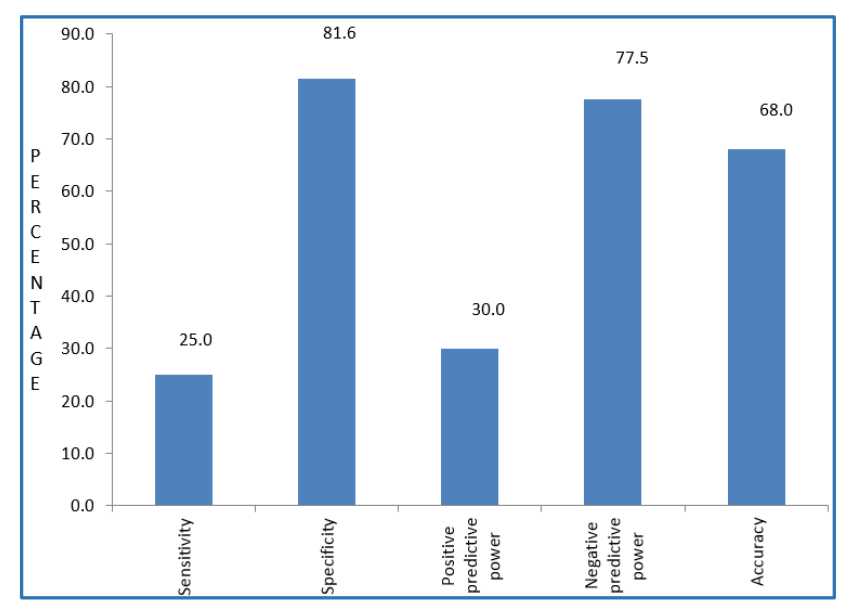

Figure V. Prediction of Macrocalcification in Thyroid Nodule being associated with Malignancy

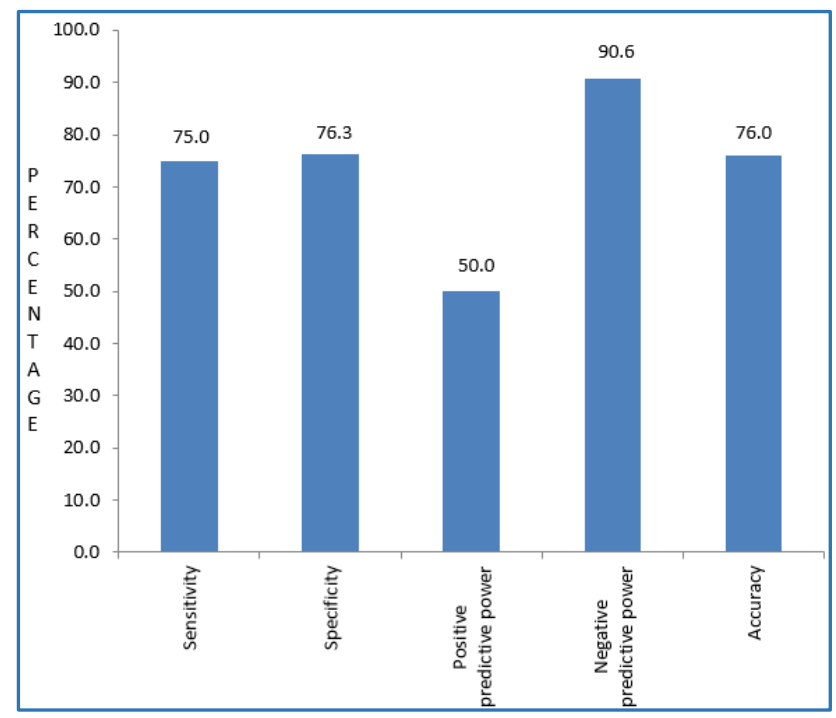

Figure VI. Prediction of Microcalcification in Thyroid Nodule being associated with Malignancy 


\section{DISCUSSION}

Based on the data obtained from the study, the efficacy of ultrasound characteristics of solitary thyroid nodules in predicting the risk of malignancy in a nodule was assessed. It was found that-

1. Presence of spiculated margins in a nodule is highly suggestive of malignancy $(100 \%$ specificity and $90 \%$ accuracy).

2. Absence of microcalcifications (Negative predictive value- $90.6 \%$ ) and a nodule which is not taller than wide (Negative predictive value- $91.4 \%$ ) in dimension has a great chance of not being malignant.

3. Ultrasonological characteristics of thyroid nodule can be used to identify malignant nodules, but cannot be used as diagnostic markers as maximum sensitivity in diagnosing a malignant thyroid nodule with these characters is $83 \%$ according to this study (Table XII).

\section{CONCLUSION}

In this prospective analysis of the sonological findings of thyroid nodule in correlation with tissue diagnosis, the most predictive of malignant tissue diagnosis were presence of hypoechogenicity, microcalcifications and nodules being taller than wide. The results of our study were encouraging, in that we were able to identify the most appreciable US features for differentiating benign from malignant solid nodules.

\section{REFERENCES}

[1] Gandolfi PP, Frisina A, Raffa M, et al. The incidence of thyroid carcinoma in multinodular goiter: a retrospective analysis. Acta Biomedica 2004;75(2):114-7.

[2] Kilfroy BA, Zheng T, Halford TR, et al. International patterns and trends in thyroid cancer incidence, 19732002. Cancer Causes Control 2009;20(5):525-31.

[3] Smith PW, Salomone LJ, Hanks JB. Thyroid. In: Townsend CM, Beauchamp RD, Evers BM. eds. Sabiston textbook of surgery: the biological basis of modern surgical practice. 19th edn. Elsevier 2012:886923.

[4] Frates MC, Benson CB, Doubilet PM, et al. Prevalence and distribution of carcinoma in patients with solitary and multiple thyroid nodules on sonography. The Journal of Clinical Endocrinology \& Metabolism 2006;91(9):3411-7.
[5] Krukowski ZH. The thyroid and parathyroid glands. In: Williams NS, Bulstrode CJK, O’Connell PR. eds. Bailey and Love's short practice of surgery. $26^{\text {th }}$ edn. CRC Press, Taylor and Francis Group 2013:741-77.

[6] Khan SA, Gafur MA, Khan MK, et al. Pattern of malignancy in clinically solitary thyroid nodule. Mymensingh Medical Journal 2012;21(1):1-7.

[7] Frates MC, Benson CB, Charboneau JW, et al. Management of thyroid nodules detected at US: Society of Radiologists in Ultrasound Consensus Conference Statement. Radiology 2005;237(3):794800.

[8] Cooper DS, Doherty GM, Haugen BR, et al. Revised American Thyroid Association Management Guidelines for patients with thyroid nodules and differentiated thyroid cancer. Thyroid 2009;19(11):1167-214.

[9] Chaudhary V, Bano S. Imaging of the thyroid: recent advances. Indian Journal of Endocrinology and Metabolism 2012;16(3):371-6.

[10] Perros P. Thyroid nodules. In: Mazzaferri EL, Harmer C, Mallick UK, et al. eds. Practical management of thyroid cancer: a multidisciplinary approach. London: Springer 2006:75-81.

[11] Moon WJ, Baek JH, Jung SL, et al. Ultrasonography and the ultrasound-based management of thyroid nodules: consensus statement and recommendations. Korean Journal of Radiology 2011;12(1):1-14.

[12] Alexander EK, Hurwitz S, Heering JP, et al. Natural history of benign solid and cystic thyroid nodules. Ann Intern Med 2003;138(4):315-8.

[13] Kim EK, Park CS, Chung WY, et al. New sonographic criteria for recommending fine-needle aspiration biopsy of nonpalpable solid nodules of the thyroid. American Journal of Roentgenology 2002;178(3):68791.

[14] Yoon DY, Lee JW, Chang KS, et al. Peripheral calcification in thyroid nodules ultrasonographic features and prediction of malignancy. Journal of Ultrasound in Medicine 2007;26(10):1349-55.

[15] Cai XJ, Valiyaparambath N, Nixon P, et al. Ultrasound guided fine needle aspiration cytology in the diagnosis and management of thyroid nodules. Cytopathology 2006;17(5):251-6.

[16] Solymosi T, Toth GL, Bodo M. Diagnostic accuracy of fine needle aspiration cytology of the thyroid: impact of ultrasonography and ultrasonographically guided aspiration. Acta Cytologica 2001;45(5):669-74. 